\title{
Neuroactive Molecules in the Etiology of Postpartum Depression An overview
}

\author{
MIH AELA GABRIELA STEFAN ${ }^{1 *}$, CARMEN ELENA CONDRAT ${ }^{1 \#}$, LAVINIA GUSA ${ }^{1 \#,}$ OANA DANIELA TOADER ${ }^{2,3 *}$, \\ ANDREI-DENNIS VOICHITOIU2,3\#, DRAGOS CRETOIU ${ }^{1,4 *}$, IOAN SORIN TUDORACHE ${ }^{*}$, NICOLAE SUCIU ${ }^{2,3}$ \\ ${ }^{1}$ Alessandrescu-Rusescu National Institute of Mother and Child Health, Fetal Medicine Excellence Research Center,120 Lacul \\ Tei Blvd., 20395, Bucharest, Romania \\ ${ }^{2}$ Alessandrescu-Rusescu National Institute of Mother and Child Health, Polizu Clinical Hospital, Department of Obstetrics and \\ Gynecology, 38-52 Gheorghe Polizu Str.,022455, Bucharest, Romania \\ ${ }^{3}$ Carol Davila University of Medicine and Pharmacy, Department of Obstetrics, Gynecology and Neonatology, 37 Dionisie Lupu \\ Str., 020021,Bucharest, Romania \\ ${ }^{4}$ Carol Davila University of Medicine and Pharmacy, Department of Cell and Molecular Biology and Histology, 8 Eroii Sanitari Str., \\ 050474, Bucharest, Romania \\ ${ }^{5}$ Titu Maiorescu University, Faculty of Medicine, 67A Gheorghe Petrascu Str, 031593, Bucharest, Romania
}

\begin{abstract}
Postpartum depression is a serious and frequent condition that affects a significant proportion of new mothers in developed countries. Despite its high prevalence and proven deleterious outcomes for both mother and child, there remains an increasing need to expand our knowledge regarding new methods that ensure the discovery of at-risk patients. Many theories have been developed over the years, mainly focusing on hormonal imbalances that occur after childbirth. This review has the purpose to analyze the existing literature and to summarize the latest findings on neuroactive molecules which may predict postpartum depression in new mothers.
\end{abstract}

Keywords: Postpartum depression, hormonal imbalances, neuroactive molecules

Nowadays, postpartum depression (PPD) is considered a serious medical disease that affects mothers during the first 4 weeks after birth. The diagnosis is made when new mothers associate at least five depressive symptoms out of nine, with a duration of 2 weeks minimum, with the nine symptoms being: depressed mood, loss of interest, loss of energy, insomnia/ hypersomnia, affected concentration/ hesitation, change in weight / appetite, psychomotor retardation/ restlessness, suicidal ideation/ attempt and repeated thoughts of death, feelings of worthlessness/ guilt [1, 2]. PPD has been shown to more likely affect women with a history of depression [3]. However, other aspects are implicated in the development of PPD, such as sociodemographic characteristics and personality traits, pregnancy complications, certain obstetric circumstances and biological factors $[3,4]$.

Pregnancy is characterized by hormonal fluctuations, with a gradual increase in estrogen and progesterone levels that is followed by a dramatic and rapid fall in these hormonal levels associated with delivery [5]. After having reached their peak, the massive reduction of estrogen and progesterone to baseline levels within 2-5 days after delivery has elicited the assumption that postpartum mood changes are generated by hormone withdrawal [6].

\section{Neuroactive molecules in pregnancy \\ 1. Pregnancy hormones}

During the first 48 hours after birth, new mothers experience a dramatic fall in estrogen, progesterone, cortisol and neurosteroid levels. Although some studies argued against the involvement of hormonal fluctuations in the etiology of PPD [7, 8], more recent evidence supports the link between steroid withdrawal and the presence of $\operatorname{PPD}[8,9]$.

Estrogen is one of the most important hormones in pregnancy, reaching a peak at the end of the third trimester which is followed by a sudden fall in the first 2-4 days after delivery $[5,6]$. Itplays a significantrole in neuromodulation by reducing neuronal excitability in the basolateral amygdala complex and regulating GABAergic inhibition. Furthermore, the estrogen elevation seen during pregnancy, which is followed by a rapid drop postpartum, has a great influence on the GABAergic and glutamatergic synaptic plasticity in the basolateral amygdala complex [10]. Successful treatment of postnatal depression through estrogen replacement therapy demonstrates its crucial role in PPD [11, 12].

Progesterone and allopregnanolone are steroids that have been correlated with PPD since their lowest falls coincide with the peak of PPD symptoms [13, 14]. Several clinical trials showed that brexanolone, an intravenous formula of allopregnanolone, had a positive effect as a possible treatment for PPD [15]. Interestingly, however, administering progestagen to women in the puerperal period has been shown to boost the risk of developing PPD [16]. These steroids exert modulatory effects not only on the hypothalamic-pituitary-adrenal axis (HPA), but also on neuroplasticity, cellular energy, immune system activation and cortical activity, mechanisms to which depression is believed to be linked [17, 18]. Moreover, progesterone is recognized as a modulator of oxytocin mRNA expression in brain regions associated with lactation and maternal behavior [19-21].

Prolactin, the hormone responsible for the regulation of lactation, is mainly synthesized and secreted by the lactotroph cells in the anterior pituitary gland, which is also involved in maternal behavior. As a result of hormonal imbalances, unsuccessful lactation frequently co-occurs with and aggravates PPD [22].

Thyroid hormones are often culpable for mood disturbances. Although there are studies that could not 
illustrate a direct link between PPD and thyroid hormone imbalance $[9,23]$, it is believed that thyroid dysfunction contributes to the development of PPD. A prospective study that was performed on 303 euthyroid pregnant women showed that $38 \%$ of those that developed postpartum thyroid disorders associated PPD which resolved with treatment of the thyroid dysfunction [24].

Oxytocin, a neuropeptide released during psychosocial interactions, is assumed to facilitate social recognition and bonding [25]. Recent studies have found that low oxytocin levels during the third trimester are linked to numerous symptoms of depression both in pregnancy and in the postpartum period, leading to inadequate breastfeeding and PPD [26, 27].

Cortisol has been extensively researched as a possible predictor in psychiatric disorders. One predictive model measuring salivary cortisol along with markers of inflammation (IL 8 and 10) revealed that an initial postpartum cortisol elevation enhances the risk of PPD [28].

Corticotropin Releasing Hormone ( $\mathrm{CRH}$ ) is also investigated for its function within the HPA axis and during stress feedback. CRH is produced by the placenta and has a sharp fall after delivery, along with the reproductive hormones. Studies have shown that elevated CRH levels are correlated with an increased risk of PPD [29, 30], some authors going as far as proposing the implementation of PPD screening programs based on $\mathrm{CRH}$ measurements [28].

Beta-endorphin is an opioid neuropeptide which has an integrative function within the HPA axis. Yim et al. showed that measuring beta-endorphin levels in the $25^{\text {th }}$ week of pregnancy could predict PPD at 9 weeks after childbirth [31].

\section{Neurotransmitters correlated with PPD}

Neurotransmitters are a distinct class of neuroactive molecules which modulate neural transmission within the nervous system. They are generally associated with depression and increasing evidence suggest they play a pivotal role in the development of PPD.

Serotonin plays a central role in the physiopathology of affective disorders, with current treatments targeting the serotonergic system. Serotonin levels are modulated not only by cortisol, but also by progesterone and estradiol, all of which undergo significant changes both during and after pregnancy [32]. PET studies have shown diminished postsynaptic 5-HT ${ }_{14}^{-}$receptor binding in PPD patients [33], while the evaluation of peripheral serotonin activity among these patients has demonstrated decreased platelet serotonin levels [34] and reduced tryptophan levels [35]. When also taking into consideration the beneficial effect of the selective serotonin reuptake inhibitors (SSRI) on PPD patients, the evidence supporting the involvement of the serotonergic system becomes clearer.

Dopamine is actively involved in the mechanisms of depression, with deficits in its activity being a possible underlying cause of it [36]. Dopaminergic activity is regulated by various brain structures such as the basolateral complex and the ventral subiculum [37], but also by ovarian hormones, mainly estrogen, which has been shown to decrease dopamine uptake, especially in the nigrostriatal and mesolimbic systems [38].

Norepinephrine and epinephrine play important roles in affective regulation and have been associated with emotional disorders such as depression and anxiety. However, current research is unsure whether depression and anxiety necessarily require a deficiency in these catecholamines, with particular studies actually indicating an excess of these molecules $[39,40]$. Hormonal fluctuations underwent during and after pregnancy greatly influence the synthesis and metabolism of these neurotransmitters, mostly through their impact on the central nervous system [41].

Glutamate has been reported to have a significant role in predicting major depression as a result of a glutamatergic dysregulation occurring in the medial prefrontal cortex [42]. Glutamate levels are mostly influenced by the fluctuation of female hormones during the menstrual cycle [43]. Several studies have pointed out the glutamatergic dysfunction witnessed in PPD patients [42, 44].

Gamma-aminobutyric acid (GABA) is the dominant neurotransmitter in the hypothalamus. Estrogen withdrawal in the postpartum period seems to impair the GABAergic and glutamatergic synaptic transmission, as well as the plasticity in the basolateral amygdala complex [1], while high concentrations of progesterone impede the amygdala activity in a manner comparable to that of benzodiazepines [45].

\section{Monoamine Oxidase A (MAO-A)}

MAO-A is an enzyme that mediates the deamination of amines like serotonin, dopamine and norepinephrine [46] . MAO-A appears to be excessively active in people suffering from depression, which would explain the reduced levels of these neurotransmitters among these patients. This theory was supported by PET studies highlighting the increased activity of MAO-A in depressed people's brains [47]. In PPD patients, Sacher et al showed a firm correlation between elevated MAO-A levels and depressive symptoms in postpartum women [48].

\section{Conclusions}

Postnatal emotional changes vary from baby blues to severe psychosis. Although etiology remains rather ambiguous, it is clear that external risk factors act in combination with hormonal variations and neurotransmitter dysregulation. This literature review is meant to highlight the necessity for further investigation into the neurobiology of postnatal psychiatric changes that will deepen the insight into postpartum depression, therefore contributing to the ultimate goal of developing new approaches for superior prevention and treatment measures.

\section{References}

1.YANG R, ZHANG B, CHEN T, ZHANG S, CHEN L. Postpartum estrogen withdrawal impairs GABAergic inhibition and LTD induction in basolateral amygdala complex via down-regulation of GPR30. European neuropsychopharmacology : the journal of the European College of Neuropsychopharmacology. 2017;27(8):759-72.

2.MUGHAL S, SIDDIQUI W. Postpartum Depression. StatPearls. Treasure Island (FL): StatPearls Publishing; 2019.

3.ABDOLLAHI F, LYE M-S, MD ZAIN A, SHARIFF GHAZALI S, ZARGHAMI $M$. Postnatal depression and its associated factors in women from different cultures. Iran J Psychiatry Behav Sci. 2011;5(2):5-11.

4.BLOM EA, J ANSEN PW, VERHULST FC, HOFMAN A, RAAT H, JADDOE VW, et al. Perinatal complications increase the risk of postpartum depression. The Generation R Study. BJOG : an international journal of obstetrics and gynaecology. 2010;117(11):1390-8.

5.KUMAR P, MAGON N. Hormones in pregnancy. Niger Med J. 2012;53(4):179-83.

6.ABOU-SALEH MT, GHUBASH R, KARIM L, KRYMSKI M, BHAI I. Hormonal aspects of postpartum depression. Psychoneuroendocrinology. 1998;23(5):465-75. 
7.BLOCH M, MEIBOOM H, LORBERBLATT M, BLUVSTEIN I, AHARONOV I, SCHREIBER S. The effect of sertraline add-on to brief dynamic psychotherapy for the treatment of postpartum depression: a randomized, double-blind, placebo-controlled study. The Journal of clinical psychiatry. 2012;73(2):235-41.

8.PASKOVA A, JIRAK R, MIKESOVA M, ADAMCOVA K, FARTAKOVA Z, HORAKOVA V, et al. The role of steroids in the development of postpartum mental disorders. Biomedical papers of the Medical Faculty of the University Palacky, Olomouc, Czechoslovakia. 2014;158(3):3614.

9.BLOCH M, DALY RC, RUBINOW DR. Endocrine factors in the etiology of postpartum depression. Comprehensive psychiatry. 2003;44(3):23446.

10.VOSE LR, STANTON PK. Synaptic Plasticity, Metaplasticity and Depression. Curr Neuropharmacol. 2017;15(1):71-86.

11.GREGOIRE AJ, KUMAR R, EVERITT B, HENDERSON AF, STUDD J W. Transdermal oestrogen for treatment of severe postnatal depression. Lancet (London, England). 1996;347(9006):930-3.

12.AHOKAS A, KAUKORANTA J, WAHLBECK K, AITO M. Estrogen deficiency in severe postpartum depression: successful treatment with sublingual physiologic 17beta-estradiol: a preliminary study. The J ournal of clinical psychiatry. 2001;62(5):332-6.

13.HARRIS B, LOVETT L, NEWCOMBE RG, READ GF, WALKER R, RIAD-FAHMY D. Maternity blues and major endocrine changes: Cardiff puerperal mood and hormone study II. BMJ . 1994;308(6934):949-53. 14.OSBORNE LM, GISPEN F, SANYAL A, YENOKYAN G, MEILMAN S, PAYNE J L. Lower allopregnanolone during pregnancy predicts postpartum depression: An exploratory study. Psychoneuroendocrinology. 2017;79:116-21.

15.KANES S, COLQUHOUN H, GUNDUZ-BRUCE H, RAINES S, ARNOLD $R$, SCHACTERLE A, et al. Brexanolone (SAGE-547 injection) in postpartum depression: a randomised controlled trial. Lancet (London, England). 2017;390(10093):480-9.

16. LAWRIE TA, HOFMEYR GJ , DE JAGER M, BERK M, PAIKER J, VILJ OEN E. A double-blind randomised placebo controlled trial of postnatal norethisterone enanthate: the effect on postnatal depression and serum hormones. British journal of obstetrics and gynaecology. 1998;105(10):1082-90.

17.RUBINOW DR, GIRDLER SS. Hormones, heart disease, and health: individualized medicine versus throwing the baby out with the bathwater. Depression and anxiety. 2011;28(6):E1-e15.

18.PLUCHINO N, RUSSO M, SANTORO AN, LITTA P, CELA V, GENAZZANI AR. Steroid hormones and BDNF. Neuroscience. 2013;239:271-9.

19.SCHILLER CE, MELTZER-BRODY S, RUBINOW DR. The role of reproductive hormones in postpartum depression. CNS spectrums. 2015;20(1):48-59.

20.AMICO JA, CROWLEY RS, INSEL TR, THOMAS A, O'KEEFE JA. Effect of gonadal steroids upon hypothalamic oxytocin expression. Advances in experimental medicine and biology. 1995;395:23-35.

21.BROAD KD, KENDRICK KM, SIRINATHSINGHJI DJ, KEVERNE EB. Changes in oxytocin immunoreactivity and mRNA expression in the sheep brain during pregnancy, parturition and lactation and in response to oestrogen and progesterone. Journal of neuroendocrinology. 1993;5(4):435-44.

22.BERNARD V, YOUNG J, BINART N. Prolactin - a pleiotropic factor in health and disease. 2019;15(6):356-65.

23.ALBACAR G, SANS T, MARTIN-SANTOS R, GARCIA-ESTEVE L, GUILLAMAT R, SANJUAN J, et al. Thyroid function $48 \mathrm{~h}$ after delivery as a marker for subsequent postpartum depression. Psychoneuroendocrinology. 2010;35(5):738-42.

24.HENDRICK V, ALTSHULER LL, SURI R. Hormonal changes in the postpartum and implications for postpartum depression. Psychosomatics. 1998;39(2):93-101.

25.UVNAS-MOBERG K, BJ OKSTRAND E, HILLEGAART V, AHLENIUS S. Oxytocin as a possible mediator of SSRI-induced antidepressant effects. Psychopharmacology. 1999;142(1):95-101.
26.STUEBE AM, GREWEN K, MELTZER-BRODY S. Association between maternal mood and oxytocin response to breastfeeding. Journal of women's health (2002). 2013;22(4):352-61.

27.SKRUNDZM, BOLTEN M, NAST I, HELLHAMMER DH, MEINLSCHMIDT G. Plasma oxytocin concentration during pregnancy is associated with development of postpartum depression. Neuropsychopharmacology : official publication of the American College of Neuropsychopharmacology. 2011;36(9):1886-93.

28.CORWIN EJ, PAJER K, PAUL S, LOWE N, WEBER M, MCCARTHY DO. Bidirectional psychoneuroimmune interactions in the early postpartum period influence risk of postpartum depression. Brain Behav Immun. 2015;49:86-93.

29.YIM IS, GLYNN LM, DUNKEL-SCHETTER C, HOBEL C], CHICZ-DEMET A, SANDMAN CA. Risk of postpartum depressive symptoms with elevated corticotropin-releasing hormone in human pregnancy. Archives of general psychiatry. 2009;66(2):162-9.

30.ILIADIS SI, SYLVEN S, HELLGREN C, OLIVIER JD, SCHIJVEN D, COMASCO E, et al. MID-PREGNANCY CORTICOTROPIN-RELEASING HORMONE LEVELSIN ASSOCIATION WITH POSTPARTUM DEPRESSIVE SYMPTOMS. Depression and anxiety. 2016;33(11):1023-30.

31.YIM IS, GLYNN LM, SCHETTER CD, HOBEL CJ , CHICZ-DEMET A, SANDMAN CA. Prenatal beta-endorphin as an early predictor of postpartum depressive symptoms in euthymic women. J Affect Disord. 2010;125(1-3):128-33.

32.BETHEA CL, LU NZ, GUNDLAH C, STREICHER J M. Diverse actions of ovarian steroids in the serotonin neural system. Frontiers in neuroendocrinology. 2002;23(1):41-100.

33.MOSES-KOLKO EL, WISNER KL, PRICE JC, BERGA SL, DREVETS WC, HANUSA BH, etal. Serotonin 1 A receptor reductions in postpartum depression: a positron emission tomography study. Fertility and sterility. 2008;89(3):685-92.

34.MAURER-SPUREJ E, PITTENDREIGH C, MISRI S. Platelet serotonin levels support depression scores for women with postpartum depression. J Psychiatry Neurosci. 2007;32(1):23-9.

35.MAES M, CLAES M, SCHOTTE C, DELBEKE L, JACQUEMYN Y, VERKERK $R$, et al. Disturbances in dexamethasone suppression test and lower availability of L-tryptophan and tyrosine in early puerperium and in women under contraceptive therapy. J ournal of psychosomatic research. 1992;36(2):191-7.

36.BROWN AS, GERSHON S. Dopamine and depression. Journal of neural transmission General section. 1993;91(2-3):75-109.

37.BELUJ ON P, GRACE AA. Dopamine System Dysregulation in Major Depressive Disorders. Int] Neuropsychopharmacol. 2017;20(12):103646.

38.ZONANA J, GORMAN J M. The Neurobiology of Postpartum Depression. CNS Spectrums. 2014;10(10):792-9,805.

39.ROY A, PICKAR D, DE JONG J, KAROUM F, LINNOILA M. Norepinephrine and Its Metabolites in Cerebrospinal Fluid, Plasma, and Urine: Relationship to Hypothalamic-Pituitary-Adrenal Axis Function in Depression. JAMA Psychiatry. 1988;45(9):849-57.

40.HUGHES J W, WATKINS L, BLUMENTHAL JA, KUHN C, SHERWOOD A. Depression and anxiety symptoms are related to increased 24hour urinary norepinephrine excretion among healthy middle-aged women. Journal of psychosomatic research. 2004;57(4):353-8.

41.SHAPIRO GD, FRASER WD, SÉGUIN JR. Emerging risk factors for postpartum depression: serotonin transporter genotype and omega3 fatty acid status. Can J Psychiatry. 2012;57(11):704-12.

42.MCEWEN AM, BURGESS DT, HANSTOCK CC, SERES P, KHALILI P, NEW MAN SC, etal. Increased glutamate levels in the medial prefrontal cortex in patients with postpartum depression. Neuropsychopharmacology : official publication of the American College of Neuropsychopharmacology. 2012;37(11):2428-35.

43.BATRA NA, SERES-MAILO J, HANSTOCK C, SERES P, KHUDABUX J, BELLAVANCE $F$, et al. Proton magnetic resonance spectroscopy measurement of brain glutamate levels in premenstrual dysphoric disorder. Biological psychiatry. 2008;63(12):1178-84. 
44.ROSA CE, SOARES JC, FIGUEIREDO FP, CAVALLI RC, BARBIERI MA, SCHAUFELBERGER MS, et al. Glutamatergic and neural dysfunction in postpartum depression using magnetic resonance spectroscopy. Psychiatry research Neuroimaging. 2017;265:18-25.

45.BACKSTROM T, BIXO M, J OHANSSON M, NYBERG S, OSSEWAARDE L, RAGAGNIN G, etal. Allopregnanolone and mood disorders. Progress in neurobiology. 2014;113:88-94.

46.MCDERMOTT R, TINGLEY D, COWDEN J, FRAZZETTO G, J OHNSON DDP. Monoamine oxidase A gene (MAOA) predicts behavioral aggression following provocation. Proc Natl Acad Sci U S A. 2009;106(7):2118-23.
47.MEYER JH, GINOVART N, BOOVARIWALA A, SAGRATI S, HUSSEY D, GARCIA A, et al. Elevated monoamine oxidase a levels in the brain: an explanation for the monoamine imbalance of major depression. Archives of general psychiatry. 2006;63(11):1209-16.

48.SACHER J, REKKAS PV, WILSON AA, HOULE S, ROMANO L, HAMIDI $J$, et al. Relationship of monoamine oxidase-A distribution volume to postpartum depression and postpartum crying. Neuropsychopharmacology : official publication of the American College of Neuropsychopharmacology. 2015;40(2):429-35.

Manuscript received: 7.11.2018 